\title{
REFORMING INFORMED CONSENT: ON DISABILITY AND GENETIC COUNSELING
}

\author{
By Elizabeth Dietz \& Joel Michael Reynolds
}

Forthcoming in:

The Oxford Handbook of Genetic Counseling

Eds. Michael Deem, Robin Grubs, and Emily Farrow

Oxford University Press

This is a pre-print.

Please cite only from the final, forthcoming version.

\begin{abstract}
:
Informed consent is a central concept for empirical and theoretical research concerning pregnancy management decisions and is often taken to be one of the more fundamental goals of the profession of genetic counseling. Tellingly, this concept has been seen by disability communities as salutary, despite longstanding critiques made by disability activists, advocates, and scholars concerning practices involved in genetic counseling more generally. In this chapter, we show that the widespread faith in informed consent is misleading and can be detrimental to the practice of genetic counseling as guided by concerns of justice and equity. We proceed in two steps. First, we explain how informed consent is flawed as a practical concept. Second, we show how the inadequacy of informed consent illuminates the animating core of disability critiques of genetic counseling: the issue of ableism. We argue that the problem of ableism cannot be solved with informed consent because it is not a problem of information, but of epistemic frameworks. We suggest that what we call critically informed consent is better suited to move genetic counseling from being aware of the problem of ableism to becoming actively anti-ableist.
\end{abstract}

Keywords:

Disability, Genetic Counseling, Informed Consent, Ableism, Patient-Provider Communication 
Disability rights activists and scholars have long posed critiques of and challenges to prenatal genetic testing (Parens and Asch 2003). These include, for example, arguments that the practice of prenatal testing invariably judges certain disabled lives to be not worthy or less worthy of living or that its effect, regardless of questions of judgment, is the prevention of certain people with disabilities from coming into being. ${ }^{1}$ Importantly, calls for greater attention to the complexity of disability as well as calls for greater incorporation of the experiential testimony of various disability communities have for many years now also become increasingly common from inside the practice of prenatal genetic counseling (Farrelly et al. 2012; Sanborn and Patterson 2014; Madeo et al. 2011; Gould et al. 2019; Boardman 2020). Whether coming from inside or outside, these calls often assume that genetic counselors' responsibilities to disability communities revolve around dialogue, understanding, and representation. It is further assumed that remedying these communicative and symbolic issues will satisfy longstanding needs for improvement, especially with respect to communication practices designed to secure informed consent. In this chapter, we hope to build upon the profession of genetic counseling's laudable engagement with disability critiques by showing why informed consent is not enough and how this issue might be fixed. ${ }^{2}$

In short, we argue that informed consent, while undoubtedly crucial to the provision of just care, can in fact reinforce unjust epistemic frameworks - patterns of thinking - when treated as an endpoint instead of a starting point. ${ }^{3}$ We suggest that what we call critically informed consent (CIC) is needed in order for such unjust epistemic frameworks to be meaningfully addressed. Our focus in this chapter will be upon epistemic frameworks rooted in ableism. Ableism is a prejudice (analogous, but distinct from prejudices involved in sexism, racism, or homophobia, et al.) that presumes the "normal" able-body is better than an "abnormal" disabled-body. This prejudice leads to a wide range of social ramifications, from employment discrimination, to hate crimes, to poor patient-provider communication, to social oppressions that include such basic things as barring entry to a building because one uses a wheelchair for mobility or failing to provide closed captioning. In what follows, we discuss critically informed consent as a tool for anti-ableist genetic counseling, an approach to genetic counseling that is committed not just to informedness, but also to the idea that genetic counselors and their clients should acknowledge and combat how dominant epistemic frameworks shaping healthcare decision-making can perpetuate ableism. ${ }^{4}$ To be anti-ableist, genetic

\footnotetext{
${ }^{1}$ In what follows, we will purposely avoid the highly developed debates over the expressivist thesis, the open future argument, and related issues. Whatever position one takes in those debates, we take our overarching claim to hold.

${ }^{2}$ That is to say, while significant strides have been made by genetic counselors to better understand disability experiences, disability history, and disability activism, we hope to show that even an ideal form of such understanding, though important and laudable, will not go far enough. ${ }^{3}$ Patterns of thinking can involve lots of different features: concepts, ideas, principles, assumptions, biases (implicit and explicit), etc.

${ }^{4}$ By focusing on what it means to be "anti-ableist" as opposed to merely not ableist, we follow in the footsteps of scholars of racialization like Ibram X. Kendi, for whom the point is not whether or not one is racist, but what one is doing and how one acts to actively combat racism. Cf. (Kendi 2019)
} 
counselors must work towards not merely increases in information, but towards epistemic transformation.

In section one, we provide a brief overview of disability theory. We canvas longstanding debates over what disability is, why and how these debates matter for genetic counselors, and the roots of historical tensions between disability communities and genetic counselors (Madeo et al. 2011). This discussion will involve an overview of disability rights critiques of prenatal testing, the import of social and post-social models of disability, and longstanding disagreements between disability rights and abortion rights/feminist choice theory more generally (A Asch 1999; Hodgson and Weil 2012a; Parens and Asch 2003; Shakespeare 2014).

In section two, we turn to the concept of informed consent. We begin by discussing the history of informed consent in biomedicine as reaction to Tuskegee and other events of blatant medical injustice, explaining how and why "fully informed consent" has come to be invoked as an explicit goal of genetic counseling (Johnston 2017). Informed consent is often framed as an output of non-directive counseling, whereby a client becomes informed in dialogue with a counselor. Informedness is a constituent part of non-directive counseling because a client sufficiently informed in collaboration with a counselor is thought to have sufficient tools to make informed, legitimate decisions. We build on existing critiques of non-directiveness in order to complicate the role of informed consent, arguing that being fully informed is impossible and, even if it were, it is insufficient to achieve anti-ableist aims in the context of genetic counseling (Clarke 1991; 2017(A. L. Caplan 2017).

In section three, we move from critical analysis to practical recommendations. We show how CIC (1) avoids communication practices that treat obtaining informed consent as an endpoint, (2) instead embeds consent within transformative dialogue and (3) challenges ableist epistemic frameworks that unreflectively place absolute value in "individual abilities" or "capacities" (Weil 2003). ${ }^{5}$

\section{Disability Theory: A Brief History}

Prenatal genetic counseling is primarily about disability. To counsel about genetic variation, genetic mutations, or any other such concepts, is to counsel about genetic differences: the many expressions of which we ultimately describe as disabilities. But what, precisely, does that term mean? Thanks to nearly seventy years of disability activism across parts of the globe and fifty years of academic work in the interdisciplinary field of disability studies, a significant body of theoretical work and onthe-ground organizing offers tools to answer this question. In what follows, we offer a brief overview of disability studies with an eye to its relevance for genetic counselors.

${ }^{5}$ An initial qualification is in order: there are some in disability studies and other domains that take the practice of genetic counseling to be inherently and irremediably problematic. We take no position on those claims in this piece. On the contrary, we assume that we are operating in a world in which genetic counseling is a staple service for those who can access it and a world in which many (though ideally all) genetic counselors aim to practice in a way that does justice to the experiences of various disability communities. 
The concept of 'disability' is not decided by dictionaries or other practices of description. On the contrary, there is no uncontroversial definition because the concept of disability involves what Adrianne Asch calls a "boundary problem," a problem the defining stakes of which are socio-political and which cannot be determined by mere appeals to authority, whether dictionaries, experts, or what have you (A Asch 1999). This is unsurprising once one recognizes that debates over disability cut to the heart of how we understand what it means to be human and how we distinguish between differing ways of being so-hardly uncontroversial matters. This is part of the reason why arguments concerning the meaning of disability show no sign of disappearing in the many academic and policy-related fields that engage with it (Garland-Thomson 2020; Nadelhoffer 2019; Parens 2017; Timpe Forthcoming).

Yet, this presents a problem for genetic counselors. A sense of what disability means is essential for counselor-client communication. What are genetic counselors who are sensitive to the complexity of disability and sensitive to the responsibilities they have to disability communities to do, given disagreements over what disability means in the first place? To answer this question requires a brief dive into both disability theory and the more specific history of disability critiques of genetic counseling.

Disability rights critiques of prenatal testing — whether with respect to maternal blood screening, conventional genetic testing, or non-invasive prenatal genetic testshave taken many forms over the years (Hodgson and Weil 2012b; Parens and Asch 2000). One of the most basic, yet most important distinctions is between medical and social models of disability. In short, on medical models of disability, disability is an individual misfortune or tragedy due to a genetic or environmental cause. Unsurprisingly, medical models tend to construe disability as overwhelmingly negative, and adherents of this view see disability as something that ought to be cured or otherwise fixed and as something which benefits from medical intervention through elimination, correction, or the like. On social models, this idea is in more than one way turned on its head, for a fundamental distinction is made between 'impairments,' which refer to some atypicality of one's body and mind, and 'disability,' which refers to the negative social ramifications of one's impairment.

However impaired someone might be, that does not explain how they are disabled for disability is ultimately a question of how societies and bodies interact. If, for whatever reason, my form of embodiment leads me to use a wheelchair as my primary form of mobility, what disadvantages me when I run into a staircase isn't my body as much as it is those who decided to build stairs and not a ramp. What impedes the fantastic student of classics who happens to be blind from becoming a professor isn't their body as much as it is a world that does not make braille and/or audio versions of texts easily accessible. ${ }^{6}$ There is a limit to this insight, of course, for one with neuropathic pain will not necessarily fare better thanks to accessible architecture or reading materials. There are some impairments that very clearly call for a medical fix, as disability studies

\footnotetext{
${ }^{6}$ As one might imagine, the distinction between medical and social models of disability has been endlessly refined and debated over many decades. For the purposes at hand, we are merely offering the "Disability 101" version of this distinction.
} 
scholars like Susan Wendell and Tom Shakespeare have argued (Wendell 1996; Shakespeare 2014).

Still, the distinction between medical and social models of disability matters for genetic counseling and decision-making concerning reproduction more generally because while such counselling aids individual decision-making - namely, concerning the health and well-being of a potential new person - that person's ability to flourish ought to be understood not merely as a function of the presence or absence of impairment, but also in terms of the attitudes and design of the built and social world that they will come to inhabit. Consider one more example: being deaf (or Deaf - which some capitalize to emphasize Deafness as an identity with a relationship to communities centered around the use of signing) is an impairment in the sense that one's hearing is not phenotypical. What makes someone who is deaf disabled, however, is a world in which most people do not know how to communicate in American Sign Language, social norms that uncritically assume the habits, needs, and cultural practices of hearing people as opposed to nonhearing people, and the many stigmas signers face in a predominantly hearing world. Where strict adherents to a medical model might find it obvious to advocate for cochlear implants or other interventions thought to advance the presumptive good of typical hearing, those adopting a social model might advocate for the normalization of captioning, more access to American Sign Language instruction, and a recognition of the richness of Deaf culture. ${ }^{7}$

There are many theories of disability, and the distinction between medical and social models is only the most basic. However basic, this distinction still illuminates the animating conflict between disability rights and genetic counseling. Prenatal genetic counseling tends toward medical model understandings of disability because the information gleaned in the course of prenatal testing is circumscribed within the medical and the genetic; it doesn't yet bear on a person living in a socially, culturally, and historically shaped world. The decisions formed in genetic counseling spheres are by their nature related in direct ways to traits about the body, while disability in fact has a great deal to do with the societies that promote or thwart the ability of people with a wide array of bodies to flourish. An appreciation of the social model makes the following observation salient: by default, the theoretical and practical orientation of genetic counseling encourages medical model-type thinking about genetics in terms of what can be predicted about the body and in turn how medicine can fix (or not fix) whatever testing uncovers.

Let us return, then, to the heart of the issue: What are genetic counselors who wish to take seriously the complexity of disability and who also recognize a responsibility to disability communities to do? And, to make matters more complicated, what are they to do in light of ongoing disagreements concerning how to understand the concept and meaning of disability (whether in pockets of disability activism or disability studies)? The answer is more simple than it seems. Whatever model of disability is at play, the upshot of disability theory as a whole is that we live in a world saturated by

${ }^{7}$ There is significant debate over the meaning of $\mathrm{d} /$ Deafness, and the discussion here is greatly simplified. Among many possible entry-points for those wanting to learn more, see (Mauldin 2016). 
ableism, and a just world requires everyone to be actively anti-ableist. ${ }^{8}$ That is to say, we live in a world where assumptions about ability and disability run rampant, assumptions that are overwhelmingly prejudicial towards disabled people of all sorts and stripes. Ableism is not just a question of people's opinions, beliefs, or presumptions. On the contrary, ableism is baked into the way that people think about themselves and others as well as how they act — how, for example, political representation is configured, how labor laws are developed, how the built environment is constructed, etc. And, as we discuss at length in section III below, it is exceedingly rare to change how people think by merely presenting information to them. On the contrary, to change the foundation of how one experiences a given phenomenon requires transformation of how one knows, not simply adding or subtracting various pieces of "information" about it. Having now given a very cursory overview of some points of disability theory, we will turn to show how the central concepts of choice and consent too easily lead to additive, not transformative, changes. After laying out that critique, we will then develop our account of critically informed consent.

\section{Choice \& Consent}

Consent - and choice - are fundamental to the project of genetic counseling. By its nature, prenatal genetic counseling is an interpersonal exercise in informing and becoming informed. As Barbara Biesecker puts it, "the goal of reproductive genetic counseling is to promote the client's self-determination in exercising choices" (Biesecker 2001). Informed consent is both a formal procedure and a way of thinking. It is formal in that it has been codified such that clients must sign documents to indicate their understanding and choosing procedures and clinical encounters. It is a way of thinking in that genetic counseling operates via the logic that there is a certain measure of knowledge - of informedness - that authorizes a person to make autonomous and trustable decisions, and counseling can help them get there. This logic is in line with other forms of healthcare decision-making, where patients are furnished with information, and having information, demonstrated by signing informed consent paperwork, legitimizes consent and is understood to be a precondition for making independent healthcare choices. The nature of prenatal genetic testing, where the information gleaned about potential genetic abnormalities can be virtually all that is known about the specific tested fetus, raises the stakes of this process of informed consent. That is to say, virtually all that is known about a tested fetus is the information that prenatal testing offers. And the people doing the gestating, aided in understanding by genetic counselors, can use it as the predicate for significant choices. Informedness is taken as the condition sine qua non for making good significant choices, where what marks the "good" choice is the appreciation and uptake of relevant information, unconstrained by outside pressures.

${ }^{8}$ To recall from pg. one above, we here define ableism as a prejudice (analogous, but distinct from prejudices involved in sexism, racism, or homophobia) that presumes the "normal" able-body is better than an "abnormal" disabled-body. 
Of course, unconstrained choice is impossible: societal norms and values that produce the meaning of disability for any given client are also present within reproductive decision-making and the institutions that exist to support it. The history of genetic counseling bears this out. Since the mid- $20^{\text {th }}$ century, the field has operated with the effect, on the one hand, of elimination of genetic diseases leading to impairment and, on the other, with the aim of helping clients prepare and understand genetic conditions in a "neutral" manner (Biesecker 2001). Many genetic counselors have long pushed back against the elimination of impairment as an explicit goal, and while their efforts have done important work to change attitudes and pedagogical models, tension between facilitation of reproductive autonomy and the promotion of anti-ableist aims mean that the elimination of impairment is still a key outcome of much genetic testing and counseling (Hawkins et al. 2013; Mansfield, Hopfer, and Marteau 1999).

The situation is even more complex than this, however, for the reasons that cause people to end up in a genetic counselor's office mediate the kinds of choices that will be available to them in the first place. These include the catalysts for testing, such as family history or previous miscarriage or advanced maternal age, that testing occurs, the other providers involved in testing, the kinds of healthcare available to them thanks to wealth, income, and other vectors of their economic situation, and more. Economic resources beget more access to genetic testing, which on one hand represents greater access to the information upon which to base choices, and on the other, strongly predisposes making particular kinds of choices (Zhang 2020). The social contexts in which decisions predicated on genetic information are made are also constrained by factors such as the healthcare, social, and school systems available, and attitudes of family and community toward disability and care. These constraints are important because they provide context and motivations for reproductive decisions. But they also hint at how those decisions are profoundly shaped by factors well beyond individual clients. These factors include aspects of choice itself, such as the stories of choice and control told about genetic testing (Lippman 1991) and the paradox of constraint that more choice can engender (Levitt 2014). In other words, even when the purpose of genetic counseling is imagined by all parties to facilitate free and informed choice, choices are always mediated and always constrained in various ways.

\section{Informed Consent}

The practice of informed consent results from an attempt to ensure that choice is as free as possible, but, of course, the mere provision of information cannot overcome the constraints imposed by the outside world. Even the information that generates informedness is not neutral; there are necessarily decisions made about what is included, what is left out, and what is unknowable. As will be discussed in section three, critically informed consent acknowledges that the provision of information is not without bias and understood as a goal of the practice of genetic counseling, it argues that such biases must be deployed in the service of epistemic transformation: to actively shift the profession of genetic counseling toward being an anti-ableist practice. 
Genetic counselors are taught that informed consent is an important goal of their practice (Biesecker 2001; Rantanen et al. 2008). This is understandable, for a key task of genetic counseling is indeed to generate informedness: to furnish clients not only with information about the landscape of genetic knowing (what particular markers mean, how they are known, how to think about probabilistic risk, etc.) but also to offer bespoke information about clients' own genetic information. Non-directiveness is thought to be key (albeit contested), because it is a method, if not the method, by which genetic counselors convey information without inflecting it via their own values. In this light, information is imagined to shape client decisions in ways that allow for the expression of their own autonomous values. Clients need to know enough about how genetic information works in order to understand what their own information means so that they can act on it. This is the consent part of informed consent: consent is a kind of choice, and in genetic counseling and beyond, its legitimacy is authorized by virtue of it being sufficiently informed so that decisions can be trusted, both by clients and by other entities such as medical providers, family members, and the law.

Emphasis on choice, made manifest in informed consent, has an important history in genetic counseling. In biomedicine broadly, informed consent became codified as a way to prevent atrocities like those in the Tuskegee Study from happening again. The commission investigating Tuskegee found that a key procedural injustice contributing to the suffering and unnecessary syphilis infection of thousands of Black men and their families was that those men were never asked for their consent to participate in the study. In the Belmont Report, authored in response to the study, the Belmont commission outlined a mandate for what they called "respect for persons." It requires that "subjects, to the degree that they are capable, be given the opportunity to choose what shall or shall not happen to them. This opportunity is provided when adequate standards for informed consent are satisfied." (The National Commission for the Protection of Human Subjects of Biomedical and Behavioral Research 1979). This is a forceful expression of the value of individual autonomy, and the translation of a right to make decisions for oneself into medical practice. ${ }^{9}$ In this paper, we do not argue that such choosing is unimportant. Rather, we argue that it is more complicated — and less individual — than prevailing notions about informed consent suggest.

We offer this cursory gloss of the history of informed consent to point specifically to the problem of paternalism and how it historically gave rise to biomedicine's keen emphasis on individual autonomy as a solution. We understand paternalism in two senses. First, where "doctor knows best," and fails to furnish the patient with information necessary for making individual health decisions. Second, where "medicine knows best," and decides that, for example, the health of poor Black men in Tuskegee Alabama is an acceptable sacrifice in the name of population health and knowledge. Bioethics gained prominence in the USA, in particular, in large part to public reaction to Tuskegee (Jonsen 1997; Washington 2008). Bioethics' emphasis on the protection of individual autonomy, through the informed consent mechanisms outlined in

\footnotetext{
${ }^{9}$ As a reviewer rightly noted, the model of consent that initially developed in biomedicine was a research model. Importing this model into clinical care writ large (and genetic counseling, specifically) is perhaps one source of these troubles.
} 
the Belmont Report, arose to gird against both sorts of paternalism. In this way, the emphasis on protecting autonomy is understandable and needed: clients and patients are important knowers, and better suited to make decisions about their own well-being than doctors - particularly when doctors act maleficently.

At the same time, such a forceful expression of the need for choices to be free and individual disregards the ways that they often cannot be. Choices, particularly reproductive choices, do not exist in a vacuum and are rather conditioned by the reality of the world in which they sit. Attitudes about disability, the resources of available school systems and social programs, the quality of accessible healthcare, the influence of racism: all bear on such decisions. The fortification of individual autonomy, and the mere provision of more information, are inadequate responses to the inequitable milieu in which reproductive choices take place. In the case of Tuskegee, it is true that Black men were not asked for their consent to participate in trials that would leave them with untreated syphilis. But it is also the case that merely asking for their consent would not address the larger factors that rendered the trials unjust: the racism of the time and place of its occurrence, under-resourcing of local health care systems, a study design that presumed the biological difference and inferiority of Black people and justified harm in the name of confirming it. In other words, the presence of consent would not have transformed the trial, or the social systems in which it took place, into one that was ethical. Consent undertaken as an individual expression of choice is necessary, but insufficient for rendering the system in which it takes place just.

Informed consent is necessary, but also insufficient, as a mechanism to combat the paternalism that has caused long legacies of significant harm. As an individual matter, and as a way that genetic counselors can facilitate and respect the reproductive autonomy of their clients, it is certainly a worthwhile aspiration. But it should be understood as the starting point, not the ending point. Informed consent itself also transforms the messiness and interdependence of the outside world into a decision where responsibility is placed on the individual. In this way, it is a tool of simplification and responsibility shifting and a way by which some liability is shifted away from providers; it is a bureaucratic tool that we find simultaneously important and insufficient for disability justice. In response, we encourage genetic counselors to think about underlying structural injustices in order to translate their responsibilities to individual clients into transformations of consciousness: much like you aren't "racist or not racist"; but racist or anti-racist, genetic counselors should not be merely 'not ableist,' but anti-ableist. ${ }^{10}$

\section{Non-Directiveness}

Genetics in general, and genetic counseling more specifically, cannot but understand itself in relation to eugenics. Indeed, much writing on the subject begins with an explicit genealogical discussion of how and why non-directiveness came to be a guiding principle for practice (Patterson and Sattz 2002). To understand a population at the level of the

\footnotetext{
${ }^{10}$ In part three, we elaborate the stakes of this critique and offer a way of thinking both about client autonomy and the impact of social structures within which decisions are made by thinking in terms of epistemic transformation rather than information provision.
} 
genome is to facilitate its management (on at least some level), which cannot escape deliberation over values and over who and what sorts of people ought to come into being, how they should be treated, etc. Non-directiveness works to create an explicit separation between the "experts" and those making individual decisions about who comes to be and who does not. A key ethos of mainstream genetics researchers and genetic counselors is one that takes active steps to acknowledge the legacy of eugenics, implementing policies and practices that endeavor to render them impossible, outside the scope of practice, and a set of verboten and antiquated norms. Genetic counseling is motivated by the need to counter the legacy of paternalism so viciously embodied in various forms of egregiously immoral social engineering. ${ }^{11}$ But in a field whose remit is to facilitate decisions about how to act on genetic information, the question of how to do that is one that requires critical vigilance and meaningful interrogation.

Non-directiveness creates a separation between the production of genetic information and its deployment. Instead of locating knowledge about what genetic information is and means in the same hands as those who decide how to act on it - where 'act' generally implies 'decides what kinds of people should come into being'-nondirectiveness assigns genetic counselors to the role of information-providers and clients to the role of decision-makers. Non-directiveness is, of course, complicated. It is "a principle, not a goal" (Biesecker 2001); it is "a technique by which genetics professionals explore whether clients can be trusted to make autonomous decisions within a climate of uncertainty (Arribas-Ayllon and Sarangi 2014); it has "has served as the central ethos for genetic counselling for the past decades and has provided both practical and ethical guidance to professionals (Rantanen et al. 2008). In other words, non-directiveness exists not as an absolute or measurable goal, but as a disposition, a way of thinking, an orientation. It is a general sense that in order to promote client autonomy and facilitate informed consent, counseling should be non-directive. It should furnish information, answer questions, acknowledge uncertainty and complexity (and in so doing, its own impossibility) — but remain a guiding force in the background, cautioning against the harms of genetic counselors making decisions for their clients.

The social factors that produce disability also generate a responsibility for genetic counselors to transform anti-ableist ways of thinking - not merely by providing more information (though that is certainly important), but also by helping clients to think differently about disability. To be sure, our interrogation of non-directiveness is not

${ }^{11}$ The legacy of Nazi experimentation looms large in the establishment of non-directiveness as a backstop against eugenics (Resta 1997). Still, as a reviewer notes, the most immediate foil is not in fact Nazi eugenics, but instead late- $19^{\text {th }}$ and early- $20^{\text {th }}$ century social eugenics programs in the U.S. E.g., the Eugenics Record Office in the U.S.A., and Margaret Sanger's overall goals in the founding of Planned Parenthood. The reviewer writes, "Alexandra Stern and Devon Stillwell have situated historically the development of non-directive prenatal genetic counseling against the backdrop of these more coercive eugenics projects, which sought to limit reproduction among certain racial groups and persons with disabilities. But there's also the issues described by Gervais and Bosk in the "Prescribing Our Future" volume, where non-directiveness was the default mode because medical geneticists with no communication or counseling training were initially returning results to clients" (Stern 2012; Stillwell 2015; Gervais 2020; Bosk 2020). 
novel. ${ }^{12}$ On the contrary, we see this argument as building upon decades of work that has complicated, pushed back on, and otherwise transformed the centrality of nondirectiveness: our aim here is to offer a translation of those critiques into something that can be concretely deployed in practice. We thus draw upon and expand such work by arguing that non-directiveness is not only impossible, but also undesirable.$^{13}$ To be antiableist requires being directive, at least with respect to how a client is pushed to think. ${ }^{14}$ As our arguments here aim to make clear, there are ways to be directive in the practice of genetic counseling that are entirely defensible, morally, practically, and otherwise. One way that we suggest doing so is by aiming for transformation with respect to the epistemic framework within and through which a given client understands the meaning of disability.

Given their role in decisions that render judgements on the possibility and impossibility of disabled lives, genetic counselors must, we contend, take an active role in transforming their clients' larger epistemic relationship to ableism in making reproductive decisions, the communal (rather than individual) effects of those decisions, and how ableist thinking may not be a conscious facet of their analytical toolbox, but is nevertheless a presence.

\section{Critically Informed Consent}

The concept of critically informed consent is premised upon work concerning how people filter information in the fields of social epistemology and psychology. A number of common cognitive biases and habits are well-known today. For example, implicit bias refers to the way that people act on stereotypes and prejudices without realizing or intending to (Brownstein 2019). Confirmation bias describes the way that people assimilate and act on information that is consistent, rather than inconsistent, with their prior conceptions (Khan et al. 2015). Anchoring bias refers to the way that people will

\footnotetext{
${ }^{12}$ Some assert the impossibility of non-directiveness: the complexity of genetic information and the range of decisions that it potentiates couple with structural limitations on what genetic counselors can know and the inescapability of bias in human interactions to render true nondirectiveness impossible (Clarke 2017). Others note that as a mechanism for promoting autonomy, it may also fall flat: one study found that clients of lower socioeconomic status or those judged to be "highly concerned" received more directive counseling(Michie et al. 1997). In a review of arguments against the non-directiveness principle (NDP), Christoph Rehmann-Sutter summarizes them as follows: "(i) NDP can be against the best interests of the individuals concerned; (ii) NDP has ideological elements that do not adequately represent the counselling ethos; (iii) NDP was historically a defensive tool that protected the interests of geneticists against social criticism and against litigation; (iv) NDP falsely assumes individual responsibility and hides the shared responsibility of other social actors" (Rehmann-Sutter 2009).

${ }^{13}$ That is to say, undesirable at least on traditional views of non-directiveness. Consider Weil and Seymour's attempts to define non-directiveness as a positive duty of GCs as well as Deem's arguments that these end up collapsing into a broader principle of respect for autonomy (Weil 2003; Kessler 1997; Deem 2016). Our thanks to a reviewer for these insights.

${ }^{14}$ That is to say, we are not endorsing being directive in the traditional sense within genetic counseling: pushing a client toward a specific decision (much like a pediatrician would be recommending/pushing an option).
} 
too heavily focus on initial pieces of information provided to them at the expense of appropriately assessing forthcoming pieces of information (T.D. Wilson 1996). Yet, these cognitive filters do not have to do with how we understand the world as such. That is to say, they are about how we think, not about the frameworks through which we think in general. Take the following example. If I hold implicit biases concerning engineers - that they have poor social skills, are exceptional at math, and dislike ambiguity - this will affect how I interact with engineers in a host of ways. So will the matrix of social factors that have (for instance) made engineering a male-dominated field and that have tended to devalue jobs typically held by women. But even if I overcome all of those biases, the larger background beliefs at play that make the concept of an "engineer" something that is communicable remain. For example: the belief in modern scientific methods (as opposed to alternative systems of knowledge), the belief that abilities (like being good at math or "social skills") are properties of people, and the belief that knowledge exists on certain gradients (such as ranging from being clear to being opaque). Those might seem like obvious truths to most readers, but that is precisely the problem. The background or framing beliefs with which people typically operate strike them as obviously true. So, what, you might be wondering, does this have to do with critically informed consent?

The problem of ableism is not, in the end, about a lack of information concerning disability, information that would include all the studies showing many people with disabilities to have similar quality of life as non-disabled people (Amundson 2005) or information that demonstrates widespread stigma against disabled people that leads to hate crimes, underemployment, and high levels of interpersonal abuse (Sherry 2010). The problem of ableism is, at its core, about the background organization of one's knowing, judging, and valuing in general (Reynolds and Peña-Guzmán 2019). Put simply, the problem of ableism is about whether one's reflective relationship to the multifaceted phenomenon of disability is sufficiently critical or not.

Let us retrace our steps. As we discussed in the section on disability theory above, the dominant medical paradigm for conceptualizing embodied difference is between 'ability' and 'disability' or 'normality' and 'abnormality,' conceptual pairs that often amount to the same in such contexts. On the medical model, to be able-bodied and normal is assumed to be both good and a goal; to be disabled and abnormal is assumed to be both bad and to be avoided/fixed/overcome. And, given the larger socio-cultural dynamics of our current epoch, this is also the dominant paradigm with which most genetic counseling clients operate. Yet, as we argued above, this paradigm is not simply empirically dubious - it is also morally problematic. To assume that all lives lived with disability are lives worse off is the most egregious form of "common sense" ableism.

Critically informed consent takes the medical model of disability head on. But it aims not merely at what information clients have about disability, but about the framework clients use to make sense of the distinction between disability and ability in the first place. To echo above, the deeper challenge of ableism is not primarily a question of exposure to disability-positive information - whether it be in the form of social scientific studies demonstrating quality of life, anecdotes from families, or what have you. The deeper challenge of ableism is the framework in which broad value judgments can be assuredly inferred from claims about specific ability states such that responses like 
the following occur: "I never shared it [the results] with any family [members]. My dad would treat [the child] differently even though the results don't say anything definitive. If she drops a ball or says something really stupid, he would say, 'oh, there's something wrong with her; she's retarded, or she's autistic.' He would just go there (Werner-Lin et al. 2016; cf. Reynolds 2020)."

For example, one might consider oneself progressive on issues concerning disability and still think that a child with Down syndrome will live a less flourishing life and that one should not follow through with such a pregnancy. Such thinking is rooted in assumptions about what sort of well-being will follow from the "capacities" of a given individual in concert with the social reality in a given place. Disability theory, on the whole, has shown such assumptions to be more often misguided than not. For example, we know that most people with Down syndrome live happy, flourishing lives (Kaposy 2018). While social contexts of course matter, they matter for any child regardless of their disability status, and they are profoundly impacted by how that child is treated and regarded as they develop (Stramondo 2020). In other words, it is difficult to make an argument that social context will matter in categorically distinct ways between someone with Down syndrome versus someone without Down syndrome-if, that is, one refuses to commit what Adrienne Asch called the "sin of synecdoche," the practice of treating a part (like having an extra chromosome) for the whole (the varied phenotypical differences that brings about in relationship with a given social, cultural, historical context) (Adrienne Asch and Wasserman 2005). Not being born with Trisomy 21 does not necessitate any guarantees about having or not having socially valuable intellectual or social skills, about developing or not developing drug dependencies that can run any life adrift, about living with or without severe depression or anxiety, or any number of other factors. Not being born with Trisomy 21 does not necessitate guarantees about living a happy life "on the whole." And if the primary concern of parent is about the extent to which they are perceived to be "normal" and not the flourishing of their child, then we are outside of the moral sphere of reproductive ethics. ${ }^{15}$

This is why critically informed consent is a practice aimed at undermining ableism. The decision-making paradigms for much of the reproductive sphere are about "prevention," "information," and "intervention." We are suggesting that all of these can reinforce injustice against disabled people insofar as the conceptual framework that underwrites these terms is left to "common sense" about the meaning of ability and disability. To argue for CIC is not to argue that the practice of genetic counseling should stop or that it necessarily contributes to injustices against disabled people. On the contrary, to argue for CIC is to argue that how genetic differences are explained, understood, and communicated must take the problem of ableism and the epistemic frameworks underwriting it head on. ${ }^{16}$

\footnotetext{
${ }^{15}$ To want a child "like oneself" and use that as a defensible basis for one's reproductive choices is an especially egregious sort of narcissism the analysis of which we simply set to the side here. See (Rulli 2014).

${ }^{16}$ A reviewer noted, "Someone might respond that CIC embodies the very concern of nondirective counseling, and that it is just a matter of giving certain kinds of information to women or couples. In other words, what's really directive about CIC, if it doesn't aim to move the discussion in a certain direction?" As we hope to have made clear, CIC is directive in the sense of moving the
} 
We have suggested that for genetic counselors to be aware of the problem of ableism is not enough. Genetic counseling as a practice must become actively antiableist. While informed consent is undoubtedly crucial to the provision of care that both meets client needs and is attentive to concerns about justice, we have argued that when treated as an endpoint rather than as a starting point, it can reinforce existing injustices at the level of how people think. To be sure, knowledge about the lived experiences of people with disabilities is vitally important, but that knowledge must be accompanied by an understanding of how ableism operates as a habit of thought, a habit all too often operating seamlessly in the background. We will not achieve a more just world through an uncritical belief that objective facts and informed consent will on their own lead naturally toward just outcomes; on the contrary, justice requires an interrogation of how what we think of as "objective" facts are often in fact inflected with biases and operate through epistemic frameworks that support the very unjust world in which we live. It is then not merely a matter of acknowledging these biases but working against the larger epistemic frameworks through which our values, judgments, and decision-making are shaped. Practicing critically informed consent is one way for the profession of genetic counseling to more effectively work towards a just world. By doing so, it is our hope that genetic counselling will shift from being aware of the problem of ableism to being actively anti-ableist.

discussion in a certain direction: but that direction is less about a particular decision and more about the framework for thinking about ability and disability at play. 
Works Cited

Amundson, Ron. 2005. "Disability, Ideology, and Quality of Life: A Bias in Biomedical Ethics." In Quality of Life and Human Difference: Genetic Testing, Health Care, and Disability, edited by David Wasserman, Jerome Bickenbach, and Robert Wachbroit, 101-24. Cambridge Studies in Philosophy and Public Policy. Cambridge: Cambridge University Press. https://doi.org/10.1017/CBO9780511614590.005.

Arribas-Ayllon, Michael, and Srikant Sarangi. 2014. "Counselling Uncertainty: Genetics Professionals' Accounts of (Non)Directiveness and Trust/Distrust." Health, Risk \& Society 16 (2): 171-84. https://doi.org/10.1080/13698575.2014.884545.

Asch, A. 1999. "Prenatal Diagnosis and Selective Abortion: A Challenge to Practice and Policy." American Journal of Public Health 89 (11): 1649-57. https://doi.org/10/dv4cns.

Asch, Adrienne, and David Wasserman. 2005. "Where Is the Sin in Synecdoche? Prenatal Testing and the Parent-Child Relationship." In Quality of Life and Human Difference: Genetic Testing, Health Care, and Disability, edited by David Wasserman, Jerome Bickenbach, and Robert Wachbroit, 172-216. Cambridge Studies in Philosophy and Public Policy. Cambridge: Cambridge University Press. https://doi.org/10.1017/CBO9780511614590.008.

Biesecker, B. B. 2001. "Goals of Genetic Counseling." Clinical Genetics 60 (5): 323-30. https://doi.org/10.1034/j.1399-0004.2001.600501.x.

Boardman, Felicity. 2020. "Human Genome Editing and the Identity Politics of Genetic Disability." Journal of Community Genetics 11 (2): 125-27. https://doi.org/10/gjhgnd.

Bosk, Charles. 2020. "The Workplace Ideology of Genetic Counselors.” In Prescribing Our Future, edited by Dianne Bartels, Bonnie S. LeRoy, and Arthur L. Caplan, 2537. New York: Routledge. https://doi.org/10.4324/9781351328609-4.

Brownstein, Michael. 2019. "Implicit Bias." In The Stanford Encyclopedia of Philosophy, edited by Edward N. Zalta, Fall 2019. Metaphysics Research Lab, Stanford University. https://plato.stanford.edu/archives/fall2019/entries/implicit-bias/.

Caplan, Arthur L. 2017. "Neutrality Is Not Morality: The Ethics of Genetic Counseling: Ethical Challenges and Consequences." In Prescribing Our Future: Ethical Challenges in Genetic Counseling, edited by D.M. Bartels, B.S. LeRoy, and A.L. Caplan, 149-66. New York: Aldine de Gruyter.

Clarke, Angus. 2017. "The Evolving Concept of Non-Directiveness in Genetic Counselling." In History of Human Genetics: Aspects of Its Development and Global. New York, NY: Springer Berlin Heidelberg.

Deem, Michael. 2016. "Vulnerability in Genetic Counseling and the Ground of Nondirectiveness." In Vulnerability, Autonomy, and Applied Ethics, edited by Christine Straehle, 144-62. New York: Routledge. https://doi.org/10.4324/9781315647418-14.

Farrelly, Ellyn, Mildred K. Cho, Lori Erby, Debra Roter, Anabel Stenzel, and Kelly Ormond. 2012. "Genetic Counseling for Prenatal Testing: Where Is the Discussion 
About Disability?" Journal of Genetic Counseling 21 (6): 814-24.

https://doi.org/10.1007/s10897-012-9484-z.

Garland-Thomson, Rosemarie. 2020. "How We Got to CRISPR: The Dilemma of Being Human." Perspectives in Biology and Medicine 63 (1): 28-43. https://doi.org/10/ggzfh3.

Gervais, Karen Grandstrand. 2020. “Objectivity, Value Neutrality, and Nondirectiveness in Genetic Counseling." In Prescribing Our Future, edited by Dianne M. Bartels, Bonnie S. LeRoy, and Arthur L. Caplan, 119-30. New York: Routledge. https://doi.org/10.4324/9781351328609-14.

Gould, Helen, Syed S. Hashmi, Victoria F. Wagner, Katie Stoll, Kathryn Ostermaier, and Jennifer Czerwinski. 2019. "Examining Genetic Counselors' Implicit Attitudes toward Disability.” Journal of Genetic Counseling 28 (6): 1098-1106. https://doi.org/10/fwwp.

Hawkins, Anne, Ana Stenzel, Joanne Taylor, Valerie Y. Chock, and Louanne Hudgins. 2013. "Variables Influencing Pregnancy Termination Following Prenatal Diagnosis of Fetal Chromosome Abnormalities." Journal of Genetic Counseling 22 (2): 23848. https://doi.org/10.1007/s10897-012-9539-1.

Hodgson, Jan, and Jon Weil. 2012a. "Talking about Disability in Prenatal Genetic Counseling: A Report of Two Interactive Workshops." Journal of Genetic Counseling 21: 17-23. https://doi.org/10.1007/s10897-011-9410-9.

_. 2012b. "Talking about Disability in Prenatal Genetic Counseling: A Report of Two Interactive Workshops.” Journal of Genetic Counseling 21: 17-23. https://doi.org/10/dwn3rf.

Johnston, Josephine. 2017. "Supporting Women's Autonomy in Prenatal Testing." N Engl j Med, 3.

Jonsen, Albert R. 1997. "The Birth of Bioethics: The Origins and Evolution of a DemiDiscipline." Medical Humanities Review 11 (1): 9-21.

Kaposy, Chris. 2018. Choosing Down Syndrome. Cambridge: MIT Press.

Kendi, Ibram X. 2019. How to Be an Antiracist. New York, N.Y.: Penguin Books.

Kessler, Seymour. 1997. "Psychological Aspects of Genetic Counseling. XI. Nondirectiveness Revisited.” American Journal of Medical Genetics 72 (October): 164-71. https://doi.org/10/dtqfdr.

Khan, Cynthia M., Christine Rini, Barbara A. Bernhardt, J. Scott Roberts, Kurt D. Christensen, James P. Evans, Kyle B. Brothers, Myra I. Roche, Jonathan S. Berg, and Gail E. Henderson. 2015. "How Can Psychological Science Inform Research About Genetic Counseling for Clinical Genomic Sequencing?” Journal of Genetic Counseling 24 (2): 193-204. https://doi.org/10.1007/s10897-014-9804-6.

Madeo, Anne C., Barbara B. Biesecker, Campbell Brasington, Lori H. Erby, and Kathryn F. Peters. 2011. "The Relationship between the Genetic Counseling Profession and the Disability Community: A Commentary." American Journal of Medical Genetics Part A 155: 1777-85. https://doi.org/10.1002/ajmg.a.34054.

Mansfield, Caroline, Suellen Hopfer, and Theresa M. Marteau. 1999. "Termination Rates after Prenatal Diagnosis of Down Syndrome, Spina Bifida, Anencephaly, and Turner and Klinefelter Syndromes: A Systematic Literature Review.” Prenatal Diagnosis 19 
(9): 808-12. https://doi.org/10.1002/(SICI)1097-0223(199909)19:9<808::AIDPD637>3.0.CO;2-B.

Mauldin, Laura. 2016. Made To Hear: Cochlear Implants And Raising Deaf Children. Minneapolis: University of Minnesota Press.

Michie, S, F Bron, M Bobrow, and T M Marteau. 1997. "Nondirectiveness in Genetic Counseling: An Empirical Study." American Journal of Human Genetics 60 (1): 4047.

Nadelhoffer, Thomas. 2019. "Chronic Pain, Bad-Differences, and Disability Variantism." Journal of Social and Ethical Philosophy, December. https://doi.org/10.31219/osf.io/d7hmg.

Parens, Erik. 2017. "Choosing Flourishing: Toward a More 'Binocular' Way of Thinking about Disability.” Kennedy Institute of Ethics Journal 27 (2): 135-50. https://doi.org/10/gf9gbc.

Parens, Erik, and Adrienne Asch. 2000. Prenatal Testing And Disability Rights. Hastings Center Studies In Ethics. Washington, D.C.: Georgetown University Press.

_. 2003. "Disability Rights Critique of Prenatal Genetic Testing: Reflections and Recommendations." Mental Retardation and Developmental Disabilities Research Reviews 9: 40-47. https://doi.org/10.1002/mrdd.10056.

Patterson, Annette R., and Martha Sattz. 2002. "Genetic Counseling and the Disabled: Feminism Examines the Stance of Those Who Stand at the Gate." Hypatia 17: 11842. https://doi.org/10.1111/j.1527-2001.2002.tb00944.x.

Rantanen, Elina, Marja Hietala, Ulf Kristoffersson, Irmgard Nippert, Jörg Schmidtke, Jorge Sequeiros, and Helena Kääriäinen. 2008. "What Is Ideal Genetic Counselling? A Survey of Current International Guidelines.” European Journal of Human Genetics 16 (4): 445-52. https://doi.org/10.1038/sj.ejhg.5201983.

Rehmann-Sutter, Christoph. 2009. "Why Non-Directiveness Is Insufficient: Ethics of Genetic Decision Making and a Model of Agency.” Medicine Studies 1 (2): 113-29. https://doi.org/10.1007/s12376-009-0023-7.

Resta, Robert G. 1997. "Eugenics and Nondirectiveness in Genetic Counseling." Journal of Genetic Counseling 6 (2): 4.

Reynolds, Joel Michael. 2020. “'What If There's Something Wrong with Her?'-How Biomedical Technologies Contribute to Epistemic Injustice in Healthcare.” The Southern Journal of Philosophy 58 (1): 161-85. https://doi.org/10/gh52z7.

Reynolds, Joel Michael, and David M. Peña-Guzmán. 2019. “The Harm of Ableism: Medical Error and Epistemic Injustice.” Kennedy Institute of Ethics Journal 29 (3): 205-42. https://doi.org/10/ggdzqt.

Rulli, Tina. 2014. "Preferring a Genetically-Related Child." Journal of Moral Philosophy, 30.

Sanborn, Erica, and Annette R. Patterson. 2014. "Disability Training in the Genetic Counseling Curricula: Bridging the Gap between Genetic Counselors and the Disability Community." American Journal of Medical Genetics Part A 164: 190915. https://doi.org/10.1002/ajmg.a.36613.

Shakespeare, Tom. 2014. Disability Rights And Wrongs Revisited. Second edition. London; New York: Routledge. 
Sherry, Mark. 2010. Disability Hate Crimes: Does Anyone Really Hate Disabled People? Burlington, VT: Ashgate.

Stern, Alexandra. 2012. Telling Genes: The Story Of Genetic Counseling In America. Baltimore: Johns Hopkins University Press.

Stillwell, Devon. 2015. “'Pretty Pioneering-Spirited People’: Genetic Counsellors, Gender Culture, and the Professional Evolution of a Feminised Health Field, 19471980." Social History of Medicine 28 (1): 172-93. https://doi.org/10/gjhbwk.

Stramondo, Joseph A. 2020. "Disability and the Damaging Master Narrative of an Open Future.” Hastings Center Report 50 (S1): S30-36. https://doi.org/10/gg94m4.

T.D. Wilson. 1996. "A New Look at Anchoring Effects: Basic Anchoring and Its Antecedents." Journal of Experimental Psychology: General 125 (4): 387-402. https://doi.org/10/cxpc7n.

The National Commission for the Protection of Human Subjects of Biomedical and Behavioral Research. 1979. "The Belmont Report." Department of Health, Education, and Welfare. https://www.hhs.gov/ohrp/regulations-and-policy/belmontreport/read-the-belmont-report/index.html.

Timpe, Kevin. Forthcoming. "Denying a Unified Concept of Disability." Journal of Philosophy and Medicine.

Washington, Harriet A. 2008. Medical Apartheid: The Dark History Of Medical Experimentation On Black Americans From Colonial Times To The Present. New York: Anchor Books.

Weil, Jon. 2003. "Psychosocial Genetic Counseling in the Post-Nondirective Era: A Point of View." Journal of Genetic Counseling 12: 199-211. https://doi.org/10.1023/a:1023234802124.

Wendell, Susan. 1996. The Rejected Body: Feminist Philosophical Reflections On Disability. New York: Routledge.

Werner-Lin, Allison, Sarah Walser, Frances K. Barg, and Barbara A. Bernhardt. 2016. “"They Can't Find Anything Wrong With Him, Yet': Mothers' Experiences Of Parenting An Infant With A Prenatally Diagnosed Copy Number Variant (CNV)." American Journal of Medical Genetics 173 (2): 444-51. https://doi.org/10/f9ptcp. 